\title{
The procession of Hoyak Tabuik: a tourism urgency and education values in Pariaman City
}

\author{
Nanda Nelri ${ }^{1}$ \\ Program Pascasarjana Universitas Negeri Padang
}

\begin{abstract}
This article is purposed to inform the performance analysis of Hoyak Tabuik procession in Pariaman community. Hoyak Tabuik is a cultural legacy in Pariaman community, which is performed annually in Pariaman City. Recently, Hoyak Tabuik ritual procession has been a tourism interest for Pariaman goverment. In addition to cultural legacy, Hoyak Tabuik ritual also a performance that attracting tourists, either domestic or foreign tourists, to visit Pariaman as tourism object. Hoyak Tabuik procession is also has educational values in cultural aspect. Therefore, Hoyak Tabuik ritual procession is important for community and government in Pariaman City at this moment.
\end{abstract}

Keywords: Hoyak Tabuik, procession, and cultural values.

\section{PENDAHULUAN}

Indonesia memiliki beraneka ragam budaya yang merupakan kekayaan bangsa. Keanekaragaman budaya ini perlu dilestarikan dan dikembangkan secara terus menerus guna meningkatkan ketahanan budaya dan yang lebih penting adalah sebagai penunjang pariwisata. Ragam budaya itu adalah pencerminan sikap dan pola hidup masyarakat yang sudah jadi turun temurun. Nilai-nilai yang terkandung didalamnya menjadi warisan yang sangat berharga bagi masyarakat pendukungya. Selain itu, keanekaragam budaya juga merupakan daya tarik tersendiri bagi wisatawan, baik domestik maupun mancanegara (Nasroen (1971:11)

Sistem nilai budaya merupakan tingkat yang paling tinggi dan paling abstrak dari adat istiadat. Hal itu disebabkan karena nilai-nilai budaya itu merupakan konsep-konsep mengenai apa yang hidup dalam alam pikiran sebagian besar dari warga suatu masyarakat mengenai apa yang mereka anggap bernilai, berharga, dan penting dalam hidup, sehingga dapat berfungsi sebagai suatu pedoman yang memberi arah dan orientasi kepada kehidupan para warga masyarakat (Koentjaraningrat,1990:190).

Kebudayaan adalah kompleks yang mencakup pengetahuan, kepercayaan, kesenian, moral, hukum, adat istiadat dan lain kemampuan serta kebiasaan oleh masyarakat. Tradisi adalah kebiasaan sosial yang diturunkan dari suatu generasi ke generasi lainnya melalui proses sosialisasi. Tradisi menetukan nilai-nilai dan moral masyarakat, karena tradisi merupakan aturan-aturan tentang hal apa yang benar dan hal apa yang salah menurut masyarakat (Koentjaraningrat, 2008:52)

Sumatera Barat merupakan salah satu propinsi di Indonesia yang terkenal dengan corak khas kebudayaan Minangkabaunya. Membicarakan minangkabau secara umum mendalami sebuah suku bangsa dengan latar belakang sejarah, adat, budaya, tradisi, agama, kesenian, pertunjukan, kepercayaan dan segala aspek kehidupan masyarakatnya. Tabuik adalah suatu warisan budaya minangkabau berbentuk ritual upacara yang berkembang di Pariaman sejak dua abad yang lalu. Di dalam tabuik ada berbagai unsur kesenian yang terdapat di setiap rentetan caranya yaitu seni musik, seni rupa, seni teater dan seni tari, yang mempunyai makna dan simbol pada setiap bagian acaranya. 
Tabuik merupakan upacara atau perayaan mengenang kematian Hasan dan Husein. Alur ceritanya berkaitan dengan tragedi 1 Muharam sampai 10 Muharam tahun Hijriah. Upacara ini dilaksanakan untuk memperingati peristiwa berdarah yang menimpa cucu Nabi Muhammad SAW, yaitu Hasan dan Husein melawan pasukan tentara Yazid bin Muawiyah yang dikenal dengan perang Karbala (Asril, 2015).

Dalam perkembangan sejarahnya tabuik Pariaman terbagi menjadi dua, yaitu tabuik pasa dan tabuik subarang. Sekarang kedua tabuik inilah yang selalu dipertunjukan pada setiap upacara hoyak tabuik di Pariaman. Melihat eksistensi tabuik yang menarik banyak orang, sekarang tabuik tidak hanya sebagai pertunjukan tradisi akan tetapi sudah menjadi objek wisata yang sudah banyak dikenal diberbagai lapisan masyarakat tidak hanya di Pariaman akan tetapi diluar Pariaman dan sampai ke luar negeri sekalipun.

Hoyak Tabuik ini masih dilaksanakan hingga saat ini dikarenakan memiliki manfaat dalam kehidupan masyarakatnya. Beberapa manfaat ini diantaranya dilihat dari segi sosiologi, antropologi, ibadah, ekonomi dan pendidikan. Bagian yang dianggap penting dari perayaan tabuik adalah pelaksanaan pestanya yang oleh masyarakat Pariaman disebut batabuik atau mahoyak tabuik. Perayaan tabuik terdiri atas beberapa rangkaian upacara yang dimulai dari rangkaian maambiak tanah ke sungai, maambiak/manabang batang pisang, maatam, marandai, maarak jari-jari, maarak saroban, tabuik naik pangkek, maoyak tabuik, hingga ditutup dengan rangkain mambuang tabuik ke laut..

Jadi sekarang dalam pelaksanaan tradisi tabuik sejak pertama dilaksanakan hingga sekarang telah mengalami banyak perubahan. Pada zaman awal dilaksanakannya tabuik, tabuik memang dilaksanakan dan mengandung nilai agama yang tinggi, bagi para pelaku tabuik mempersiapkan acara tabuik sebagaimana merayakan hari besar agama. Namun pelaksanaan tabuik sekarang lebih kepada memperlihatkan nilai hiburan dan pariwisata Pariaman. Pelaksanaan tabuik tergantung pada kebijaksanaan pemerintah bukan wewenang anak nagari lagi. Konsekuensi dari pelaksanaan tersebut, tabuik bukan saja milik masyarakat Pariaman, tetapi sudah menjadi kebutuhan rekreatif bagi wisatawan domestik maupun mancanegara. Campur tangan pemerintah cenderung menyebabkan degradasi penyelenggaraan, baik dari segi waktu penyelenggaraan, tujuan pelaksanaan, kekhidmatan pelaksanaan, dan kesakralan dalam upacara hoyak tabuik.

Artikel ini menginformasikan hoyak tabuik dalam persoalan bagaimana pelaksanaan hoyak tabuik, pengaruhnya terhadap wisata kota Praiaman, serta menjelaskan nilai-nilai pendidikan dalam setiap prosesi hoyak tabuik.

\section{METODE}

Penelitian ini dilakukan di kelurahan kampung perak, Kota Pariaman provinsi Sumatera Barat. Penelitian ini adalah penelitian deskriptif kualitatif. Metode penelitian kualitatif adalah metode yang digunakan untuk menemukan pengetahuan yang seluas-luasnya terhadap objek penelitian pada suatu saat tertentu. Pengumpulan data dilakukan dengan turun langsung ke lapangan mewawancarai narasumber tetua tabuik, kepala dinas pariwisata pariaman, serta masyarakat pariaman. Interview atau wawancara dilakukan untuk mengumpulkan informasi tentang tabuik ini. Selain itu, data dokumentasi dan hasil studi dikoleksi oleh peneliti sebagai data penelitian.

Analisis dilakukan dengan tahapan mengoleksi data dari wawancara dan dokumentasi. Semua data pada gilirannya di seleksi untuk dianalisis, dengan mempertimbangkan permasalahan dan berpedoman pada pertanyaan penelitian serta teori pendukung. Peneliti kemudian memverifikasi data yang dianggap sahih, dan memberikan interpretasi terhadap data yang telah diverifikasi tersebut.

Keabsahan data dilakukan dengan diskusi teman sejawat, dan dengan menggunakan triangulasi. Keabsahan data dilakukan dengan memeriksa data dalam situasi yang berbeda, dan mengulang kembali menyesuaikan dengan persoalan yang sesungguhnya dipertanyakan.

\section{PEMBAHASAN}

Tabuik merupakan salah satu tradisi tahunan di dalam masyarakat Pariaman. Festival ini telah berlangsung sejak puluhan tahun lalu dan diperkirakan telah ada sejak abad ke-19 masehi. Perhelatan tabuik merupakan bagian dari peringatan hari wafatnya cucu Nabi Muhammad SAW, yaitu Hussein bin Ali yang jatuh pada tanggal 10 Muharram. Sejarah mencatat, Hussein beserta keluarganya wafat dalam perang di padang Karbala. Di Pariaman, tradisi ini unik lantaran mayoritas penduduk kota kecil yang berjarak sekitar 50 kilometer dari Padang, ibu kota Sumatera Barat itu penganut Sunni. Tradisi ini hanya dilakukan oleh masyarakat Minangkabau di kota itu, yang 
mayoritas adalah penganut Mahzab Syafii yang dibawa Syekh Burhanuddin. Menurut kisah yang diterima masyarakat secara turun temurun, ritual ini diperkirakan muncul di Pariaman sekitar tahun 1826-1828 Masehi. Tabuik pada masa itu masih kental dengan pengaruh dari timur tengah yang dibawa oleh masyarakat keturunan India penganut Syiah. Pada tahun 1910, muncul kesepakatan antar nagari untuk menyesuaikan perayaan Tabuik dengan adat istiadat Minangkabau, sehingga berkembang menjadi seperti yang ada saat ini.

Tabuik terdiri dari dua macam, yaitu Tabuik Pasa dan Tabuik Subarang. Keduanya berasal dari dua wilayah berbeda di Kota Pariaman. Tabuik Pasa (pasar) merupakan wilayah yang berada di sisi selatan dari sungai yang membelah kota tersebut hingga ke tepian Pantai Gandoriah. Wilayah Pasa dianggap sebagai daerah asal muasal tradisi tabuik. Adapun tabuik subarang berasal dari daerah subarang (seberang), yaitu wilayah di sisi utara dari sungai atau daerah yang disebut sebagai Kampung Jawa. Dan kedua tabuik inilah yang selalui dipertujukan pada setiap tahunnya di Kota Pariaman.

Tabuik berbentuk bangunan bertingkat tiga terbuat dari kayu, rotan, dan bambu dengan tinggi mencapai 10 meter dan berat sekitar 500 kilogram. Bagian bawah Tabuik berbentuk badan seekor kuda besar bersayap lebar dan berkepala "wanita" cantik berjilbab. Kuda gemuk itu dibuat dari rotan dan bambu dengan dilapisi kain beludru halus warna hitam dan pada empat kakinya terdapat gambar kalajengking menghadap ke atas. Kuda tersebut merupakan simbol kendaraan Bouraq, dalam cerita tempo dulu adalah kendaraan yang memiliki kemampuan terbang secepat kilat. Pada bagian tengah Tabuik berbentuk gapura petak yang ukurannya makin ke atas makin besar dengan dibalut kain beludru dan kertas hias aneka warna yang ditempelkan dengan motif ukiran khas Minangkabau.

Di bagian bawah dan atas gapura ditancapkan "bungo salapan" (bunga delapan) berbentuk payung dengan dasar kertas warna bermotif ukiran atau batik. Pada bagian puncak Tabuik berbentuk payung besar dibalut kain beludru dan kertas hias yang juga bermotif ukiran. Di atas payung ditancapkan patung burung merpati putih.Di kaki Tabuik terdapat empat kayu balok bersilang dengan panjang masing- masing balok sekitar 10 meter. Balok-balok itu digunakan untuk menggotong dan "menghoyak" Tabuik yang dilakukan sekitar 50 orang dewasa. Adapun rangakaian rentetan prosesi tabuik dari tabuik dibuat sampai tabuik dibuang ke laut yaitu sebagai berikut:

\section{Upacara 'Maambiak Tanah'}

Prosesi ini biasanya dilaksanakan oleh seorang laki - laki yang berasal dari keluarga pengurus 'tabuik'. Sang pengambil tanah ini memakai kain putih. Kain putih ini berarti kejujuran dari kepemimpinan Husein. Prosesi ini dilakukan pada sore hari tanggal 1 Muharam. Dalam prosesi ini terbagi kedalam dua kelompok, yaitu kelompok 'tabuik' Pasa (balai) dan kelompok 'tabuik' Subarang. Prosesi ini akan diiringi aloh arak - arakan yang ditemani dengan dentuman gandang tasa.

Prosesi ini dilakukan dengan mengambil segumpal tanah dari dasar sungai. Pengambilan tanahnya harus di anak sungai yang berbeda dan berlawan arah antara kelompok Pasa (balai) dan kelompok Subarang. Pangambilan tanah ini bukanlah hanya mengambil tanah saja. Tetapi ini merupakan simbol dari pengambilan jasad Hasan Husein yang mati syahid.Tanah yang telah diambil tersebut lalu dibungkus dengan kain putih yang bersih. Hal tersebut seolah - seolah seperti mengafani jasad dari Hasan - Husein. Selanjutnya tanah tersebut diletakkan dalam sebuah periuk yang indah. Periuk yang telah berisikan tanah tadi dibungkus kembali dengan kain putih yang bersih. Setelah itu disimpan di 'daraga'.

\section{Upacara 'Manabang Batang Pisang'}

Prosesi ini dilakukan pada tanggal 5 Muharam. Pada tengah malam orang - orang kampung akan pergi ke hutan beramai- ramai. Mereka akan mencari pohon pisang, yang kemudian ditebas. Dalam prosesi ini batang pohon pisang harus terpotong dalam satu tebasan. Yang menebas batang pisang haruslah laki - laki yang menggunakan semacam baju silat. Untuk menebasnya, biasanya penebas menggunakan pedang yang sudah diasah agar tajam setajam - tajamnya. Kemudian batang pisang tersebut dibawa ke 'deraga'. Sesampainya di 'deraga' ditanamkan dekat dengan pusara. Prosesi ini melambangkan apa yang dilakukan oleh musuh - musuh Allah terhadap Hasan - Husein.

\section{Upacara 'Maatam'}

Prosesi ini dilakukan pada tanggal 7 Muharam. Prosesi maatam dilaksanakan setelah sholat dzuhur oleh orang (keluarga) penghuni rumah tabuik. Secara beriringan mereka berjalan mengelilingi daraga sambil membawa peralatan ritual tabuik ( jari-jari, sorban, pedang husein,dll) sambil menangis meratap-ratap. Hal ini sebagai pertanda kesedihan yang dalam atas kematian husein, sedangkan daraga adalah hakekat dari kuburan husein.

\section{Upacara 'Maarak Jari-Jari (Panja)'}


Prosesi ini dilakukan pada tanggal 7 Muharam, hari yang sama dengan upacara 'maatam panja'. Panja merupakan sebuah kubah yang terbuat dari kertas kaca dan bingkai bambu. Kertas ini di gambari dengan tangan dengan jari - jari yang putus. Di dalam panja diberikan lilin. Panja akan diarak keliling kampung. Kelompok ini akan memperlihatkan kepada seluruh masyarakat bagaimana kesedihan mereka. Dan ini meruapakan perlambangan bahwa jari - jari Hasan - Husein telah dipotong oleh musuh. Mereka akan menceritakan bagaiman kezaliman sang penguasa, Yazid bin Muawiyah, terhadap Hasan - Husein. Mereka keliling kampung dengan diiringi oleh gandang tasa dan 'tabuik lenong'. 'Tabuik lenong' adalah sebuah miniatur 'tabuik' yang diletakkan diatas kepala seorang pria.

\section{Upacara 'Maarak Soroban'}

Prosesi ini dilakukan pada keesokan harinya, yaitu tanggal 8 Muharam. Prosesi ini tidak jauh beda dengan prosesi yang sebelumnya, 'maarak panja'. Rombongan akan keliling kampung. Memperlihatkan bagaimana kejamnya perlakuan penguasa saat itu, Yazid bin Muawiyah, kepada cucu nabinya sendiri, Hasan - Husein. Diiringi dengan tabuhan gandang tasa dan diikuti oleh pria yang mengenakan 'tabuik lenong'. Prosesi ini melambangkan bahwa kepala dari Hasan - Husein telah dipenggal bak hewan.

\section{Upacara 'Tabuik Naik Pangkek'}

Prosesi ini berada di hari utama yaitu tanggal 10 Muharam. 'Tabuik naik pangke' dilaksanakan pada pagi hari. Pada pagi hari 'tabuik' dari kedua wilayah, Pasa (balai) dan Subarang, akan dikeluarkan dari rumahnya. Kedua 'tabuik' itu akan diarak hingga bertemu. Setelah bertemu tabuik pun akan dipasangkan menjadi satu kesatuan 'tabuik' yang utuh. Selanjutnya tabuik dihoyak sepanjang hari.

\section{Upacara 'Hoyak Tabuik'}

Sepanjang hari tanggal 10 muharam mulai pada pukul 09.00 wib, dua tabuik yaitu tabuik pasa dan tabuik subarang disuguhkan ketengah ppengunuung pesta hoyak tabuik sebagai hakekat peristiwa perang karbala. Acara hoyak tabuik akan berlangsung hingga sore hari secara lambat laun tabuik diusung menuju pinggir pantai seiiring turunnya matahari.

\section{Tabuik Dibuang Kelaut}

Menjelang sore, dimulai penyatuan tabuik pasa dan tabuik subarang (tabuik naik pangkat), kedua tabuik itu diarak keliling Kota Pariaman. Masing-masing tabuik dibawa oleh delapan orang pria atau lebih. Sampai akhirnya kedua tabuik dipertemukan kembali di Pantai Gandoriah. Pertemuan kedua tabuik di Pantai Gandoriah ini merupakan acara puncak dari upacara tabuik, karena tidak lama setelah itu, kedua tabuik akan diadukan (sebagaimana layaknya perang di Karbala). Menjelang matahari terbenam kedua tabuik dibuang kelaut yaitu Pantai Gandoriah.

Prosesi pembuangan tabuik ke laut merupakan suatu bentuk kesepakatan masyarakat untuk membuang segenap sengketa dan perselisihan antar mereka. Selain itu, pembuangan tabuik juga melambangkan terbangnya buraq yang membawa jasad husein ke surga.

Tabuik berbentuk bangunan bertingkat tiga terbuat dari kayu, rotan, dan bambu dengan tinggi mencapai 10 meter dan berat sekitar 500 kilogram. Bagian bawah Tabuik berbentuk badan seekor kuda besar bersayap lebar dan berkepala "wanita" cantik berjilbab. Kuda gemuk itu dibuat dari rotan dan bambu dengan dilapisi kain beludru halus warna hitam dan pada empat kakinya terdapat gambar kalajengking menghadap ke atas. Kuda tersebut merupakan simbol kendaraan Bouraq, dalam cerita tempo dulu adalah kendaraan yang memiliki kemampuan terbang secepat kilat. Pada bagian tengah Tabuik berbentuk gapura petak yang ukurannya makin ke atas makin besar dengan dibalut kain beludru dan kertas hias aneka warna yang ditempelkan dengan motif ukiran khas Minangkabau.

Di bagian bawah dan atas gapura ditancapkan "bungo salapan" (bunga delapan) berbentuk payung dengan dasar kertas warna bermotif ukiran atau batik. Pada bagian puncak Tabuik berbentuk payung besar dibalut kain beludru dan kertas hias yang juga bermotif ukiran. Di atas payung ditancapkan patung burung merpati putih.Di kaki Tabuik terdapat empat kayu balok bersilang dengan panjang masing- masing balok sekitar 10 meter. Balok-balok itu digunakan untuk menggotong dan "menghoyak" Tabuik yang dilakukan sekitar 50 orang dewasa.

Sebelum memasuki acara puncak tabuik, pemerintah Kota Pariaman mengisi acara 1-10 muharam dengan berbagai mcam acara yaitu diantaranya, lomba lagu daerah, tari-tarian, acara musik, drama, dll. Acara ini disi berbagai kalangan, termasuk siswa siswi seklolah yang ada Di kota Pariaman. Partsipasi siswa siswi dalam mengeisi acara ini dialakukan oleh pemerintah Pariaman, agar mereka merasakan apa makna dalam Tabuik sendiri. Pada upacara penegmbilan tanah, upacara ini mengikutsertakan siswa siswi yang membawa pawai obor ketempat penegmbilan tanah. 
Dari rentetan prosesi pelaksanaan hoyak tabuik terdahulunya sudah mengalami perubahan. Pembuangan tabuik ke laut tidak harus tanggal 10 muharam, tetapi menunggu jadwal libur yaitu hari minggu, mungkin tanggal 11,12,13,14, atau tanggal 15 Hijriah. Maksud perubahan jadwal tersebut dilakukan sesuai kepentingan dan tujuan pariwisata. Karena pada hari tersebut pengunjung akan lebih banyak berkenjung untuk menyasikan acara puncak prosesi hoyak tabuik yang merupakan acara tradisi yg dilakukan pada setiap tahunnya oleh masyarakat kota Pariaman. Hal ini dilakukan untuk mendorog dan menunjang sektor pariwisata Kota Pariaman. Tidak hanya berpengaruh kepada sektor pariwisata saja, perubahan ini juga berdampak kepada kehidupan ekonomi masyarakat Paraiaman. Karena pada saat acara hoyak tabuik banyak warga yang berdagang dikawasan pesisir Pantai Gandoriah.

\section{KESIMPULAN}

Tabuik adalah suatu warisan budaya di Kota Praiaman. Tabuik merupakan upacara atau perayaan mengenang kematian Hasan Husein, tetapi kemudian berkembang menjadi pertunjukan budaya khas Pariaman. Bagian yang dianggap penting dari perayaan tabuik adalah pelaksanaan pestanya yang oleh masyarakat Pariaman disebut batabuik atau mahoyak tabuik. Adapun nilai-nilai yang terkandung dalam rentetan prosesi tabuik yaitu nilai sosial, budaya, ekonomi, agama, dan nilai pendidikan. Dalam pelaksanaan tabuik sejak pertama dilaksanakan hingga sekarang telah mengalami perubahan, baik dari segi waktu pelaksanaannya dan kesakralan. Namun pelaksanaan tabuik sekarang lebih kepada memperlihatkan nilai hiburan atau pariwisata untuk menarik pengunjung baik dari domestik maupun mancanegara untuk datang ke Pariaman.

\section{REFERENSI}

Asril, (2015). Peran Gandang Tasa Dalam Membangun Semangat dan Suasana Pada Pertunjukan Tabuik di Pariaman.Insitut Seni Indonesia: Padang Panjang : Tesis

Koentjaraningrat. (2008). Metode Penelitian Masyarakat. PT. Gramedia. Jakarta

Koentjaraningrat. (2009). Pengantar Ilmu Antropologi. Jakarta: Rineka Cipta.

Maran, Imran. (1989). Dasar-dasar Sosial Budaya Pendidikan. Jakarta: Departemen Pendidikan dan Kebudayaan. Mulyana, Dedi. (2004). Metodologi Penelitian Kualitatif. Bandung: Remaja Rosda Karya.

Nasroen. (1971). Dasar Filsafah Adat Minangkabau. Jakarta: Bulan Bintang.

Neong, Muhajir. (1990). Metodologi Penelitian Kualitatif. Yogyakarta: Rake Sarasin.

Rahmanelli. (2007). Upacara Ritual Tabuik dalam Konteks Perubahan Budaya di Kota Pariaman. Padang. Tesis. Universitas Negeri Padang. 